\title{
Nutritional supplementation for diabetic retinopathy
}

Hannah E Bartlett \& Frank Eperjesi

Ophthalmic Research Group, School of Life and Health Sciences, Aston University, Birmingham B4 7ET, UK.

Corresponding author: Hannah Bartlett

Ophthalmic Research Group

School of Life and Health Sciences

Aston University

Birmingham

B4 7ET

UK

Tel: $\quad+441212044182$

Fax: $\quad+441212044048$

Email: H.E.Bartlett@aston.ac.uk

\begin{abstract}
Oxidative stress is increased in the diabetic retina, and this could be due to increased generation of free radicals, or an impaired anti-oxidant defence system. The potential role of the nutraceuticals Pycnogenol ${ }^{\circledR}$, Ginkgo biloba extract, vitamin E, vitamin C, lipoic acid, genistein, Aloe vera, and chromium in the treatment or prevention of diabetic retinopathy is discussed. Although epidemiological evidence does not support a relationship between antioxidant intake and reduced risk for diabetic retinopathy, intervention trials indicate that further research is needed to clarify the role of Pycnogenol ${ }^{\circledR}$, Ginkgo biloba extract, and vitamin E in the management of this condition.
\end{abstract}




\section{Introduction}

This literature review will provide an insight into the potential role of nutritional supplementation in type 2 diabetes. Diabetes is a disorder of the metabolism of cbohydrates, lipids, and proteins in which the body cannot produce insulin or cannot use it to its full potential. This can lead to damage of several different tissues, particularly those that are insulin insensitive such as the retina, kidney and nerves (Kowluru and Kennedy, 2001)

Ttype 1 diabetes occurs in children and young adults, $40-50 \%$ of whom will go on to develop significant microvascular complications. Ttype 2 diabetes is most common, accounting for $90-95 \%$ of all diabetic patients (Watkins et al., 2003b).

Both forms cause long-term complications such as cataract, retinopathy, neuropathy (peripheral nerve damage), and nephropathy (progressive loss of renal function). Over 135 million people are affected by diabetes worldwide. In the US, $0.3 \%$ of the population develop type I diabetes by the time they are 20 years of age and 800000 new cases of type II diabetes are diagnosed annually (American Diabetes Association, 2004). Diabetes therapy is centred upon the control of blood sugar. Retinopathy is the most common complication, resulting in registrable blindness for over 10000 diabetic people per year in the USA (Fong et al., 2004). All forms of diabetes are characterised by chromic hyperglycaemia that results in disease-specific microvascular changes. These changes result in retinopathy, nephropathy, and a variety of debilitating neuropathies. Accelerated macrovascular atherosclerotic change is also associated with diabetes; people with diabetes are at higher risk of myocardial infarction, stroke, and limb amputation (Brownlee and Gd, 2001).

\section{Histological changes in diabetic retinopathy}

The structure of the retinal microvessels is directly related to maintenance of an effective blood-retinal barrier and is formed by the tight junctions between endothelial cells. The endothelial cells of retinal vessels are nonfenestrated and are joined by tight junctions. The retinal microvessel wall also contains pericytes, which provide mechanical support and stability, as well as a basement membrane that surrounds the endothelial cells and pericyes, and is made up of glycoprotein and collagen. 
The three types structural microvessel changes that occur in diabetes are basement membrane thickening, selective pericyte loss, and endothelial cell changes.

Basement membrane thickening is a known complication of diabetes (Ashton and T, 1974) and studies of dientes-affected versus control eyes have shown that there is a $2-5$ fold increase in thickness in people affected by diabetes. This process is thought to be related to accerleration of the normal ageing process, although the underlying cause is not clear. Vacuole formation and altered collagen synthesis may also occur. Autopsy studies have found a 1:1 ratio between pericytes and endothelial cells in non-diabetic eyes compared with a 1:4 ratio in diabetic eyes (Cogan and Kuwabara, 1967).

A localised, limited proliferative response of endothelial cells is thought to result in small, round outgrowths from the vessel wall (Forrester et al., 1993). These are known as saccular aneurysms, or dot haemorrhages, and are the one of the earliest ophthalmoloscopic signs of retinopathy (Ashton and T, 1974). Pericyte loss may play a part in this process, either by creating a weak point in the vessel wall, or via removal of their inhibitory control of endothelial proliferation (Forrester et al., 1993).

\section{Biochemical events relating to the development of diabetic retinopathy}

Hyperglycaemia refers to a condition in which there is an excessive amount of glucose circulating the blood plasma. Glucose levels vary throughout the day, and before and after meals, however, the normal blood glucose level in fasting adults is $4-7 \mathrm{mmol} / \mathrm{L}$. A patient who consistently measures above $7 \mathrm{mmol} / \mathrm{L}$ is considered hyperglycaemic, and one who consistently measures below $4 \mathrm{mmol} / \mathrm{L}$ is considered hypoglycaemic. There is a relationship between hyperglycaemia and microvascular diabetic complications in both type 1 and type 2 diabetes (Shamoon et al., 1993, Turner et al., 1998); both hyperglycaemia and insulin resistance appear to play are part in the development of these complications (Turner et al., 1998, Wei et al., 1998, Ebara et al., 2000, Ginsberg, 2000).

Hyperglycaemia is thought to lead be involved in the development of diabetic complications via four pathways; increased formation of advanced glycation end-products (AGEs), the polyol pathway, activation of protein kinase $\mathrm{C}(\mathrm{PKC})$ isoforms, and increased hexosamine pathway flux. 
Increased formation of AGEs

The formation of AGEs is thought to be a hyperglycaemia-related process (Brownlee and Gd, 2001) that is implicated in the development of diabetic retinopathy (McCance et al., 1993, Murata et al., 1997, Chibber et al., 1997, Yamagishi et al., 2002, Nakamura et al., 2003, Boehm et al., 2004, Fosmark et al., 2006). Diabetic microand macrovascular disease has been shown to improve with removal of AGEs (Forbes et al., 2003, Bierhaus et al., 2004, Hammes et al., 2003, Stracke et al., 2001). Formation of AGEs involves the attachment of glucose (or other sugar molecules) to a protein or lipid molecule in the absence of the controlling action of an enzyme. When the addition of sugars to protein or lipid molecules is controlled, it is termed glycosylation; glycation is an uncontrolled process that negatively effects the functioning of biomolecules. Glycation that takes place within the body is termed endogenous glycation, and occurs in the bloodstream to absorbed simple sugars such as glucose, fructose and galactose. Red blood cells are involved in glycation, and glycated haemoglobin levels are use in the monitoring of blood sugar in diabetes.

Following glycation, a series of reactions take place, resulting in the irreversible development of AGEs (John and Lamb, 1993, Raj et al., 2000), some of which are involve in the development of age-related conditions such as type II diabetes. This chain-reaction can also result in the production reactive oxygen species (ROS) (Huebschmann et al., 2006) including the highly oxidative radical, hydrogen peroxide. Higher amounts of AGEs are found in diabetic retinal vessels (Stitt et al., 2002) than in controls. AGE formation can occur within a week in endothelial cells exposed to high glucose levels (Brownlee and Gd, 2001). Proteins modified by AGEs in endothelial cells include basic fibroblast growth factors (Giardino et al., 1994) and those involved in macromolecular endocytosis (Shinohara et al., 1998). The increase in endocytosis induced by hyperglycaemia is prevented by overexpression of the enzyme glyoxalase 1 (Shinohara et al., 1998), which is also implicated in pericyte loss and capillary regression (Maisonpierre et al., 1997).

\section{Polyol pathway}


This pathway has been implicated in diabetic complications, especially retinopathy, nephropathy, and neuropathy, and is also known as the sorbitol-aldose reductase pathway. Aldose reductase is the first enzyme in the polyol pathway, and it catalyses the NADPH-dependent reduction of a wide range of carbonyl compounds, including glucose (Brownlee, 2001). Unused glucose enters the polyol pathway, when aldose reductase reduces it to sorbitol. High blood glucose levels result in excessive production of sorbitol. Activation of the polyol pathway results in decreased production of reduced NADP+ and oxidised NAD+, which are co-factors in redox reactions within the body. This may result in increasing concentrations of triose phosphate (Williamson et al., 1993), which may in turn increase production of AGEs (Brownlee, 2001). Reduction of glucose to sorbitol results in consumption of $\mathrm{NADPH}$, which is required for regenerating reduced glutathione and nitric oxide. Nitric oxide is also known as 'endothelium derived relaxing factor', or EDRF, and signals dilation of blood vessels, and glutathione acts as an antioxidant. This may result in induced intracellular oxidative stress, and is a likely mechanism by which the increased activity of the polyol pathway contributes to disease pathogenesis (Lee et al., 1999). Sorbitol may also glycate nitrogens on protein such as collagen resulting in the production of advanced glycation end products (AGEs).

Most cells of the body require insulin to allow glucose to gain entry to them, but the cells of the retina, kidneys, and nervous system are insulin independent, which means that glucose moves freely across their cell membranes. Glucose that is not used for energy production enters the polyol pathway. When glucose levels are normal, this does not cause a problem as aldose reductase has a low affinity for glucose at normal levels. However, when glucose levels are high, sorbitol is able to accumulate, NADP is used up, and so there is less NADPH available for other cellular processes. It has been proposed that when sorbitol accumulates within cells, water is drawn in due to osmosis, although the sorbitol concentrations measured in diabetic vessels are too low to cause osmotic damage (Brownlee, 2001).

In summary, excessive activation of the polyol pathway, in a hyperglycaemic state, leads to increased accumulation of sorbitol, increased production of reactive oxygen species, and decreased levels of glutathione and nitric oxide. These factors are thought to be involved in the development of damage to retinal microvessels in diabetic retinopathy. 


\section{Activation of protein kinase $C$}

The protein kinase $\mathrm{C}(\mathrm{PKC})$ family is made up of eleven isoforms, nine of which are activated a lipid second messenger called DAG. Intracellular hyperglycaemia increases the amount of DAG in the retina of diabetic animals. This increased level of DAG in cultured vascular cells (Xia et al., 1994) and in the retina of diabetic animals (Koya and King, 1998), activates PKC. Hyperglycaemia may also indirectly increase activation of PKC via ligation AGE receptors (Portilla et al., 2000) and increased activity of the polyol pathway (Keogh et al., 1997). It has been suggested that abnormal activation of PKC is involved in the decreased production of nitric oxide in experimental diabetes (Craven et al., 1994), as well as decreased production of nitric oxide in smooth muscle cells that is indeced by hyperglycaemia (Ganz and Seftel, 2000). Inhibition of nitric oxide production may also contribute to increased microvascular matrix protein accumulation (Craven et al., 1997).

\section{Hexosamine pathway}

Throughflow of excess glucose through the hexosamine pathway may also contribute to the complications of diabetes (ref 74). Hyperglycaemic activation of this pathway may result in changes to gene expression ans protein function, which together may contribute to the pathogenesis of diabetic complications (Brownlee and Gd, 2001)

\section{Hyperglycaemia and oxidative stress}

Hyperglycaemia and diabetes have been associated with increased levels of oxidative stress (Guigliano et al., 1996). Hyperglycaemia has been shown to increase the production of superoxide by endothelial cells, in a study of cultured endothelial aortic cells (Giardino et al., 1996). Superoxide may activate all four pathways of hyperglycaemic damage. Superoxide partially inhibits the glycolytic enzyme GAPDH, which results in a build up of glucose, glucose-6-phosphate, and frustose-6-phosphate and means that they are available to enter into the polyol and hexosamine pathways. Inhibition of GAPDH also results in a build-up of glyceraldehydes-3phosphate, which in turn results in increased production of DAG from DHAP, resulting in increased activation of PKC. Glyceraldehyde-3-phosphate is also converted to methylglyoxal, the main intracellular AGE precursor. 
Increased flux through the hexosamine pathway increases protein modification, and increased flux through the polyol pathway consumes NADPH and depletes GSH (Brownlee and Gd, 2001).

Oxidative stress has been found to be associated with diabetic complications in some studies (Sinclair et al., 1992, Sinclair et al., 1991). Chemically, oxidation refers to the removal of electrons and, when it occurs within the body, it can result in the formation of cytotoxic chain reactions. Reactive oxygen species (ROS) is a term used to describe some types of free radicals, hydrogen peroxide and singlet oxygen, which are all capable of damaging membrane lipids, proteins, nucleic acids, and carbohydrates via oxidation (Beatty et al., 2000).

There are exogenous and endogenous substances that can provide protection from ROS damage. These are often referred to as antioxidants. Singlet oxygen is scavenged by vitamin A and other retinoids, as well as betacarotene (Levin et al., 1997) and other carotenoids (Di Mascio et al., 1989). The superoxide anion radical is efficiently removed by the enzyme superoxide dismutase (SOD), which in the cell mitochondria contains manganese, and in the cytosolic compartment contains copper and zinc. Hydrogen peroxide is metabolised by the selenium-containing enzyme, glutathione peroxidase. When there is an imbalance between the amounts of ROS being produced and the amount of exogenous and endogenous antioxidants available i.e. more ROS than antioxidants, a state of oxidative stress exists (McCord, 2000).

Ocular tissues are particularly susceptible to oxidative damage. The transparency of the cornea, aqueous humour, lens and retina allow continuous exposure to light, which along with aging, inflammation, air pollutants and cigarette smoke, has been shown to result in an increase in the production of ROS (Machlin and Bendich, 1987, Borish et al., 1987).

The retina is particularly vulnerable to oxidative damage because of its abundance of polyunsaturated fatty acids, the occurrence of phagocytosis within the retinal pigment epithelium, and the fact that it has much higher blood flow than other tissues. Polyunsaturated fatty acids are predominantly found in photoreceptor outer membranes, and are readily oxidised (Machlin and Bendich, 1987, Beardsley, 1991, Van der Hagen et al., 1993). Phagocytosis results in the production of ROS and high blood flow increases the availability of oxygen. 
In diabetes, oxidative stress may result from:

- Excessive oxygen radical production from the auto-oxidation of glucose (Woff et al., 1991)

- Glycated proteins (Mullarkey et al., 1990) (glycation is the result of a reducing sugar molecule, such as fructose or glucose, bonding to a protein or lipid molecule without the controlling action of an enzyme).

- Stimulation of ctyochrome P450-like activity as a result of excessive nicotinamide adenine dinucleotide phosphate-oxidase (NADPH) production via glucose metabolism (Jain, 1989)

- Ketone body acetoacetate (Jan et al., 1998)

- Glycation of antioxidant enzymes (Baynes and Thorpe, 1996, Guigliano et al., 1996).

The vitamin antioxidant network

A system of vitamin antioxidant nutrients exists to neutralize ROS. Vitamin C reacts with superoxide in the aqueous phase and Vitamin $E$ reacts with peroxy radicals in the lipophilic phase. In the process, vitamins $C$ and E themselves become free radicals. However, they have aromatic ring structures, which delocalize the unpaired electron and are therefore less reactive. They also form part of the antioxidant network, in which vitamin $\mathrm{C}$ is able to regenerate vitamin E from the vitamin E radicals (Packer, 2001a).

Alpha lipoic acid is a vitamin-like antioxidant that is soluble in fat and water (Kagan et al., 1990). It is manufactured within the body and is also found in food such as liver and yeast. Dihydrolipoic acid (DHLA), a powerful metabolic antioxidant, is formed when alpha lipoic acid is reduced by enzymes. It has an important role in antioxidant defence through maintenance of high levels of the reduced (potent) forms of vitamins $\mathrm{C}$ and $\mathrm{E}$. Alpha-lipoic acid also boosts cellular levels of glutathione, a major cellular antioxidant. Levels of glutathione decline with age, and low levels are associated with higher incidence of disease in older people. Glutathione concentrations are recognised as a predictor of the susceptibility to disease as well as a marker of biological age (Packer, 2001b).

\section{Diabetic retinopathy}


Hyperglycaemia is a major causative factor in the development of endothelial dysfunction, and is a precursor to peripheral vascular complications including changes to vascular permeability and retinal blood flow and thickening of basement membranes (Kowluru and Kennedy, 2001). Capillaries are lined with endothelial cells that are closely associated with pericytes. Hyperglycaemia results in loss of endothelial cells and pericytes, which are contractile and provide tone to the capillaries. If these vascular changes are confined within the retina, then they are termed background retinopathy. If, however, new vessels break through the internal limiting membrane of the retina, the change is termed proliferative retinopathy. In this case, new vessels grow on the surface of the retina and adhere to the posterior layer. Contraction of the vitreous can lead to traction on these vessels and subsequent retinal detachment (Watkins et al., 2003a).

Method: literature review

We identified pertinent articles on use of nutritional supplementation for type 2 diabetes published in peerreviewed journals, through a multi-staged, systematic approach. In the first stage, a computerized search of the PubMed database (National Library of Medicine) and the Web of Science database was performed to identify all relevant articles published between 1950 and December 2007. Terms and words used for the search included 'diabetes mellitus, type 2', 'diabetes mellitus', 'nutrition', 'antioxidants', 'Pycnogenol', 'chromium', 'magnesium', 'selenium', 'vanadium', 'niacinamide', 'vitamin $\mathrm{B}_{3}$ ', 'cobalamin', 'vitamin $\mathrm{B}_{12}$ ', 'ascorbic acid', 'vitamin c', 'tocopherol', 'vitamin E', 'carnitine/ or acetylcarnitine/ or palmitoylcarnitine', 'I carnitine', 'folic acid/ or pteroylpolyglutamic acids/ or tetrahydrofolates'. Searches were limited to 'humans' and 'optimised therapy'. In the second stage all abstracts were examined to identify articles that described randomised controlled trials investigating nutritional intervention in people with type 2 diabetes. Studies were excluded if there intervention contained more than one nutrient and/or was not for oral use. Copies of the entire articles were obtained, where possible. Bibliographies of the retrieved articles were manually searched with use of the same search guidelines. In the third stage, articles were reviewed and information relating to the use of nutritional supplementation for type 2 diabetes was incorporated in to the manuscript. The literature search was not limited to the English language, although no translation was required

\section{Nutraceuticals and diabetic retinopathy}

The term 'nutraceutical' refers to chemical components of common foods that are claimed to have a medicinal effect.

\section{Outcome measures}


Plasma and urine $F(2)$-isoprostanes

The isoprostanes are prostaglandin-like compounds formed in vivo from the free radical-catalyzed peroxidation of arachidonic acid without the activity of cyclooxygenase enzyme. They are accurate markers of lipid peroxidation in both animal and human models of oxidative stress (Morrow 1996). Their association with coronary artery calcification is thought to be supportive of the hypothesis that oxidative damage is involved in the early development of atherosclerosis (Gross et al., 2005).

\section{Fasting plasma glucose and two-hour oral glucose tolerance test}

These tests measure of how well glucose is cleared from the blood. In order to carry out a fasting plasma glucose test, the patient must have been fasting for $8-12$ hours, at which time a baseline blood sample is taken. In order to measure two-hour oral glucose tolerance (OGT), the patient is then given a glucose solution to drink. The standard dose since the late 1970s has been 1.75 grams of glucose per kilogram of body weight, to a maximum dose of $75 \mathrm{~g}$. A blood sample for measurement of glucose is teken at 2 hours, and sometimes at further two-hour intervals depending on the setting.

The World Health Organisation classifies diabetes mellitus as:

- Fasting plasma venous glucose $\geq 7.0 \mathrm{mmol} / \mathrm{l}(126 \mathrm{mg} / \mathrm{dl})$

OR

- 2-hour OGTT (with $75 \mathrm{~g}$ glucose) plasma venous glucose $\geq 11.1 \mathrm{mmol} / \mathrm{l}$ (200 mg/dl) (World Health Organisation, 2006).

\section{Red blood cell sorbitol levels}

Accumulation of sorbitol is thought to occur in response to hyperglycaemia and be one of the biochemical events implicated in the development of diabetic complications (Brownlee, 2001).

Insulin sensitivity/resistance

Insulin resistance occurs when the body doesn't respond as well to the insulin that the pancreas is making to help glucose leave the blood and enter the body's cells. An insulin resistance test measures the amount of glucose necessary to compensate for an increased insulin level without causing hypoglycemia (Defronzo et al., 1979).

Thiobarbituric acid reactive substances (TBARS)

These substances are low-molecular-weight end products, probably malondialdehyde, that are formed during the decomposition of lipid peroxidation products. The plasma or urine concentration of the TBARS is used as an index of lipid peroxidation and oxidative stress (Cherubini et al., 2005).. 
$\underline{\text { Serum albumin and urine albumin excretion rates }}$

Proteins from the blood can escape into the urine when the filters of the kidney, called glomeruli, are damaged. Sometimes the term albuminuria is used when a urine test detects albumin specifically. Microalbuminuria is defined as excretion of between 30 and $300 \mathrm{mg}$ of albumin a day in the urine. Microalbuminuria is an important prognostic marker for kidney disease in diabetes mellitus. It is also a useful biological marker for individuals who are at high risk of cardiovascular events (Yuyun et al., 2005). Microalbuminuria is diagnosed either on 24-hour urine collections (20 to $200 \mu \mathrm{g} / \mathrm{min}$ ) or, more commonly, if elevated concentrations ( 30 to $300 \mathrm{mg} / \mathrm{L}$ ) on at least two occasions. Low blood albumin levels (hypoalbuminemia) can also result from excessive unrinary excretion of albumin (Kaysen et al., 1995).

Fasting blood insulin levels

Can indicate loss of insulin sensitivity

$\mathrm{HbA1c}$

$\mathrm{HbA1c}$ is a test that measures the amount of glycosylated hemoglobin in the blood. Glycosylated hemoglobin is a molecule in red blood cells that attaches to glucose. Higher levels of glycosylated hemoglobin are related to higher levels of glucose in the blood. The test gives a good estimate of how well diabetes has been controlled over the last 2 or 3 months.

Malondialdehyde levels

Malondialdehyde is the end-product of lipid peroxidation by reactive oxygen species. It is therefore used as a biomarker for oxidative stress

Glutathione peroxidase 
Glutathione peroxidase is the general name of an enzyme family with peroxidase activity whose main biological role is to protect the organism from oxidative damage..

Superoxide dismutase

The enzyme superoxide dismutase catalyzes the dismutation of superoxide into oxygen and hydrogen peroxide. As such, it is an important antioxidant defense in nearly all cells exposed to oxygen.

Ex vivo assessment of eicosanoid sysnthesis

Eicosanoid is the collective term for oxygenated derivatives of essential fatty acids (Beare-Rogers et al., 2001)

Pycnogenol $^{\circledR}$

Pycnogenol $^{\circledR}$ is a standardised extract of bark of the French maritime pine (Pinus pinaster), and has been shown to protect endothelial cells against oxidant-induced injury (Wei et al., 1997). Pycnogenol promotes a protective antioxidant state by upregulating important enzymatic and nonenzymatic oxidant scavenging systems (Wei et al., 1997). It is one of the most potent natural antioxidants, and also has an affinity for proteins such as collagen (Roghdewald, 2002). Pycnogenol® significantly decreases nitrogen monoxide generation, and it is thought that this function may result from a combination of several biological activities including its ROS and nitrogen monoxide scavenging activity, inhibition of the enzyme nitric oxide syntase (iNOS), and inhibition of iNOS-mRNA 
expression (Virgili et al., 1998).Pycnogenol® can readily cross the blood-brain barrier to provide antioxidant protection to central nervous system tissue. This property differentiates it from other known antioxidants. Its antioxidant potential is associated with anti-inflammatory action, whereas its affinity for collagen may be responsible for the reduction of pathologically increased capillary permeability (Roghdewald, 2002).

Supplementation of conventional diabetes treatment with Pycnogenol @ has been shown to lower glucose levels and improve endothelial function (Liu et al., 2004). Pycnogenol ${ }^{\circledR}$ is licensed in France for the treatment of diabetic retinopathy.

Pycnogenol $^{\circledR}$ has been investigated for use in the treatment and prevention of diabetic retinopathy in several trials over the past 50 years. All of these studies showed that Pycnogenol ${ }^{\circledR}$ slowed retinopathy progression and result in a partial recovery of lost visual acuity.

In one investigation, a six-month double masked trial of Pycnogenol ${ }^{\circledR}$ versus Dexium 500 (calcium dobesilate) was carried out with 32 type 1 and 2 diabetic participants. The pharmacology of Dexium is similar to that of Pycnogenol ${ }^{\circledR}$ except that it does not have such a high binding affinity collagen.

The Pycnogenol ${ }^{\circledR}$ group were instructed to take $120 \mathrm{mg} /$ day for the first six days and then $80 \mathrm{mg} /$ day for the remainder of the trial. Pycnogenol ${ }^{\circledR}$ was found to reduce exudates in both eyes of five participants, compared with just one Dexium-treated participant. The authors concluded that Pycnogenol ${ }^{\circledR}$ may also be beneficial for improvement of the visual field (Leydhecker, 1986).

Another double-masked, placebo controlled trial investigated the effect of $150 \mathrm{mg} /$ day Pycnogenol ${ }^{\circledR}$ on objective parameters in patients with retinopathies associated with diabetes, atherosclerosis, and hypertension (Spadea and Balestrazi, 2001). Examination of the ocular fundus showed a significant improvement in those treated with Pycnogenol $^{\circledR}(p=0.003$, left eyes; $p=0.043$, right eyes $)$, compared with the placebo, and electrophysiology and fluoroangiography was improved in the treatment group $(p<0.001)$. The group taking Pycnogenol ${ }^{\circledR}$ also experienced a significant reduction in vascular permeability and an improvement in the blood-retinal barrier. No significant change in visual field was found and no side effects were reported by either group. 
In 1988, Plantorgan conducted a multi-centre field study with 1169 participants with diabetic retinopathy (Arzneimittel, 1988). It was of six-month duration and the main objective was to assess the effect of Pycnogenol ${ }^{\circledR}$ on the progression of visual acuity. Deterioration of visual acuity ceased, and in some cases improved. The improvement was noted after three months of supplementation and continued over a further three months. Side effects were reported by $1.45 \%$ of participants, and included stomach problems, headache, nausea, and dizziness.

\section{Vitamin $E$}

Alpha-tocopherol is the most effective antioxidant of the vitamin E group, and protects against lipid peroxidation (Machlin, 1980). Vitamin E exists in four common forms: alpha-tocopherol, beta-tocopherol, gamma-tocopherol, delta-tocopherol (Drevon, 1991).

The most predominant form in the human retina and plasma is alpha-tocopherol (Alvarez et al., 1987, Handelman et al., 1985), which is also the most effective scavenger of free radicals (Burton. and Ingold, 1984). Vitamin $E$ is found in high concentrations within the retina (Dilley, 1970, Hunt, 1984), and as the major lipidsoluble antioxidant present in all cellular membranes, it protects against lipid peroxidation (Machlin, 1980) and may also have a role as a quencher of singlet oxygen Plasma concentration is known to reduce with age while high dietary intake of vitamin E can increase concentration in the retina (Seddon, 1999).

The potential role of vitamin E supplementation in the control of diabetic retinopathy relates to increased levels of oxidative stress in the vascular endothelium of diabetic patients (Baynes and Thorpe, 1996, Guigliano et al., 1996). Antioxidant treatment may improve endothelial cell dysfunction in diabetes (Timimi et al., 1998). 
An eight-month randomised controlled crossover trial reported that oral vitamin E treatment (1800 IU/day) appeared to be effective in normalising retinal haemodynamic abnormalities and improving renal function in type I diabetic patients with a short disease duration without affecting glycaemic control (Bursell et al., 1999).

Epidemiological studies have shown that vitamin E improves insulin sensitivity in short-term supplementation trials (Paolisso et al., 1994, Paolisso et al., 1993).

\section{Vitamin C}

Vitamin C (ascorbic acid) is a chain-breaking antioxidant, i.e. it scavenges ROS directly and prevents the propagation of chain reactions that would otherwise lead to a reduction in protein glycation. It also prevents the breakdown of nitric oxides, and decreases the oxidation of low density lipoproteins (LDL) (Young et al., 1995). Vitamin $\mathrm{C}$ has been shown to affect retinal blood flow in animal models and human supplementation trials (Cunningham et al., 1994, Visnon et al., 1989, Wang et al., 1995, Yue et al., 1989). It is water soluble, reduces platelet aggregation (Wilkinson et al., 1999), and may be important in lowering blood pressure (Taddei et al., 1998).

Vitamins $\mathrm{C}$ and $\mathrm{E}$ both protect against oxidative stress caused by non-enzymatic glycation, autoxidative glycosylation, and metabolic stress in diabetic people (Baynes and Thorpe, 1999). Vitamin C also reduces diabetes-induced sorbitol accumulation in the erythrocytes and significantly reduces lipid peroxides in the erythrocytes and plasma (Cunningham et al., 1994).

However, epidemiological studies investigating the relationship between micronutrient intake and retinopathy do not support supplementation as a treatment or prevention strategy. The San Luis Valley Diabetes Study reported no protective effect and highlighted the potential for deleterious effects of antioxidant (including vitamin C) use in diabetic retinopathy (Mayer-Davis et al., 1998). The Third National Health and Nutrition Examination Survey reported no association between serum ascorbic acid and alpha-tocopherol concentrations and retinopathy in people with type 2 diabetes (Millen et al., 2003). Both studies were, however, limited by cross-sectional designs, 
while the San Luis Valley study was further limited by the collection of 24-hour recall data, which is unlikely to reflect long-term food intake.

A prospective study was designed using participants from the Atherosclerosis Risk in Community Study, to investigate the relationship between diabetic retinopathy and intake of vitamins $C$ and $E$ (Millen et al., 2004). No relationship was demonstrated, although misclassification of nutrient intake for food frequency questionnaires, exclusion of subjects for whom data was missing, misclassification of specific lesions of retinopathy and a lack power to detect an association when the effect of vitamins $C$ and $E$ on retinopathy was modest, are very likely to have limited the findings of this study. (Millen et al., 2004).

\section{Lipoic acid}

Lipoic acid is a naturally occurring antioxidant with potent ROS-scavenging activity (Packer et al., 1995). It has the unusual property of being an ROS scavenger in its oxidised state (Chidlow et al., 2002), and has been shown to quench:

- Hydroxyl radicals

- Hypochlorous acid

- Singlet oxygen

- Nitric oxide radical

- Peroxynitrite

- Hydrogen peroxide.

Alpha-lipoic acid and dihydrolipoic acid work in a redox couple, and together have other antioxidant properties including chelation of transition metals and the regeneration of other antioxidants such as glutathione, vitamin C and vitamin $\mathrm{E}$ (Biewenga et al., 1997). Alpha-lipoic acid has been shown to protect the retina against ischaemiareperfusion injuries in vivo and in vitro (Chidlow et al., 2002). Ischaemic injury to the retina is considered to be one of the major causes of visual loss, and occurs in conditions such as retinopathy of prematurity and glaucoma (Hayreh, 2001, Osborne et al., 2001), as well as diabetic retinopathy. Alpha-lipoic acid is available on prescription in Germany and is widely used in the treatment of diabetic neuropathy. 
The effect of lipoic acid on nitric oxide-mediated vasodilation in diabetic patients has been investigated, and compared with the well-recognised effect of vitamin C (Heitzer et al., 2001). Alphalipoic acid has been shown to increase insulin sensitivity in type-2 diabetes (Jacob et al., 1999), and has the added benefits of being readily absorbed from the diet in a bioavaliable form and being welltolerated (Packer et al., 1995). Large doses (at least $600 \mathrm{mg} /$ day) are well tolerated and no serious adverse consequences have been recorded. A review of the clinical trials of alpha-lipoic acid in the treatment of diabetic neuropathy suggests that there is some evidence to support its use and beneficial effects on acute symptoms and progression have been reported (Ziegler et al., 1999).

\section{Phytoestrogens: Genistein}

Genistein, is an isoflavenoid that is found in soybeans (Naim et al., 1973). It is a naturally occurring tyrosine kinase inhibitor (Akiyama et al., 1987), but also has several other properties including acting as an antioxidant (Wei et al., 1993, Wei, 1994, Wei et al., 1996) by protecting against lipid peroxidation and by scavenging hyperoxide and superoxide anions (Jha et al., 1985, Wei et al., 1993).

Genistein has been shown to inhibit proliferation of vascular endothelial cells and tumour cells, (Akiyama et al., 1987, Fotsis et al., 1995, Steele et al., 1995).

Long-term oral administration of genistein in diabetic rats inhibits retinal vascular leakage (Nakajima et al., 2001). This finding supports the use of tyrosine kinase inhibition in the treatment of diabetes-induced retinal vascular leakage. Genistein may also be useful in the prevention of neuronal degeneration in the inner retina that results from ischaemic injury, as systemic administration has been shown to improve ischaemia-reperfusioninduced retinal degeneration (Hayashi et al., 1997).

\section{Chromium}

It is known that chromium deficiency will lead to impaired glucose tolerance due to insulin resistance i.e. insulin is produced in correct amounts but is not taken up properly. A chromium deficiency can also contribute to hyperglycaemia (Cefalu and $\mathrm{Hu}$, 2004). It has been suggested that chromium supplements might have beneficial 
effects in the management of type 2 diabetes where the primary pathological change is a decline in insulin response (insulin resistance).

Some reports have suggested that chromium supplements may increase insulin sensitivity and improve glucose tolerance and other measures of diabetic control in patients with type 2 diabetes. A placebo-controlled, doublemasked randomised pilot study demonstrated that supplementation with chromium picolinate in combination with biotin in patients with poorly controlled diabetes receiving anti-diabetic therapy improved glucose management and several lipid measurements (Singer and Geohas, 2006). The investigators concluded that this type of supplementation may have the potential to improve lipid metabolism in people with poorly controlled diabetes. A meta-analysis of randomised controlled trials investigating the effect of chromium supplementation on glucose and insulin response on healthy individuals and those with diabetes reported no evidence of effect in nondiabetic subjects. The data for diabetic subjects were reported to be inconclusive (Althuis et al., 2002).

However, a more recent review of clinical studies of chromium picolinate supplementation in diabetes mellitus found that 13 out of 15 studies reported a significant improvement in at least one outcome of glycaemic control. Pooled data showed substantial reductions in hyperglycaemia and hyperinsulinaemia, equating to a reduced risk of disease complications, with chromium picolinate supplementation (Broadhurst and Domenico, 2006). There is support in the literature for the safety and therapeutic value of chromium picolinate supplementation for the management of cholesterolaemia and hyperglycaemia in people with diabetes.

\section{Plant extracts- Aloe vera}

The leaves of the Aloe vera plant contain a high concentration of anthraquinone compounds that have been used historically as a cathartic. Within the leaves there is a gel, which has been used as a food and to treat burns and other wounds (Grindlay and Reynolds, 1986).

Aloe vera gel extract has been shown to have antioxidant properties in diabetic rats (Rajasekaran et al., 2005). Oral administration of Aloe vera gel extract to diabetic rats resulted in a reduction in fasting blood glucose levels, 
plasma and tissue cholesterol, triglycerides, free fatty acids, phospholipids, and a significant improvement in plasma insulin (Rajasekaran et al., 2006). Aloe vera gel and phytosterols derived from the gel are reported to have a long-term blood glucose level control effect (Tanaka et al., 2006). Randomised controlled trials are needed to determine any treatment effect of Aloe vera for diabetes mellitus.

\section{Conclusions}

Epidemiological evidence does not support a relationship between antioxidant intake and reduced risk for diabetic retinopathy, however, intervention trials indicate that further research is needed to clarify the role of Pycnogenol $^{\circledR}$ (Leydhecker, 1986, Spadea and Balestrazi, 2001, Arzneimittel, 1988), Ginkgo biloba extract (Huang et al., 2004) and Vitamin E (Bursell et al., 1999).It has been suggested that the lipid-soluble vitamin $E$ could be combined with a water-soluble antioxidant such as glutathione or $\mathrm{N}$-acetylcysteine, to increase its efficacy in improvement of blood flow (Jain, 1999). Pycnogenol ${ }^{\circledR}$ is reported to protect vitamin $E$ from oxidation (Cossins et al., 1998), and also prevents platelet activity in humans without increasing bleeding time (Puttner et al., 1999). There is also support for use of vitamin C supplementation (van den Enden et al., 1995, Williamson et al., 1993, Baynes and Thorpe, 1999), and potential for development of a nutritional supplement aimed specifically at diabetic patients, containing Pycnogenol ${ }^{\circledR}$, Ginkgo biloba extract, vitamin E, or vitamin C, or a combination of these. 


\section{References}

Akiyama, T., Ishida, J., Nakagawa, S., et al. (1987). Genistein, a specific inhibitor of tyrosine-specific protein kinases. Journal of Biological Chemistry 262, 5592-5595.

Althuis, M., Jordan, N., Ludington, E. and Wittes, J. (2002). Glucose and insulin responses to dietary chromium supplements: a meta-analysis. American Journal of Clinical Nutrition 76, 148-155.

Alvarez, R., Liou, G. and Fong, S. (1987). Levels of alpha- and gamma-tocopherol in human eyes: evaluation of the possible role of IRBP in intraocular alpha-tocopherol transport. Am J Clin Nutr 46, 481-487.

American Diabetes Association (2004). All about diabetes (webpage): http://www.diabetes.org/aboutdiabetes.jsp. Accessed January 2004.

Arzneimittel, P. (1988). Pygnoforton bei diabetischer retinopathie. Plantorgan study report., Hanover, Germany.

Ashton, N. and T (1974). VASCULAR BASEMENT-MEMBRANE CHANGES IN DIABETIC-RETINOPATHY MONTGOMERY LECTURE, 1973. British Journal of Ophthalmology 58, 344-366.

Baynes, J. and Thorpe, S. (1996). The role of oxidative stress in diabetic complications. Current Opinion in Endocrinology 3, 277-284.

Baynes, J. and Thorpe, S. (1999). Role of oxidative stress in diabetic complications: a new perspective on an old paradigm. Diabetes 48, 1-9.

Beardsley, T. (1991). The A Team. Vitamin A and its cousins are potent regulators of cells. Sci Am, 16-19.

Beare-Rogers, J., Dieffenbacher, A. and Holm, V. (2001). Lexicon of lipid nutrition (IUPAC technical report). Pure and Applied Chemistry 73, 685-744.

Beatty, S., Koh, H. H., Henson, D. and Boulton, M. (2000). The role of oxidative stress in the pathogenesis of age-related macular degeneration. Survey of Ophthalmology 45, 115-134.

Bierhaus, A., Haslbeck, K. M., Humpert, P. M., et al. (2004). Loss of pain perception in diabetes is dependent on a receptor of the immunoglobulin superfamily. Journal of Clinical Investigation 114, 1741-1751.

Biewenga, G., Haenen, G. and Bast, A. (1997). The pharmacology of the antioxidant alpha-lipoic acid. General Pharmacology 29, 315-331.

Boehm, B. O., Schilling, S., Rosinger, S., et al. (2004). Elevated serum levels of N-epsilon-carboxymethyl-lysine, an advanced glycation end product, are associated with proliferative diabetic retinopathy and macular oedema. Diabetologia 47, 1376-1379.

Borish, E., Prior, W. and Venuugopal, S. (1987). DNA synthesis is blocked by cigarette tar-induced DNA single strand breaks. Carcinogenesis 8, 1517-1520.

Broadhurst, C. L. and Domenico, P. (2006). Clinical studies on chromium picolinate supplementation in diabetes mellitus - A review. Diabetes Technology \& Therapeutics 8, 677-687.

Brownlee, M. (2001). Biochemistry and molecular cell biology of diabetic complications. Nature 414, 813-820.

Brownlee, M. and Gd (2001). Biochemistry and molecular cell biology of diabetic complications. Nature 414, 813820. 
Bursell, S.-E., Clermont, A., Aiello, L. M., et al. (1999). High-dose vitamin E supplementation normalises retinal blood flow and creatinine clearance in patients with type I diabetes. Diabetes Care 22, 1245-1251.

Burton., G. and Ingold, K. (1984). Autoxidation of biological molecules: 1: The antioxidant activity of vitamin $\mathrm{E}$ and related chain-breaking phenolic antioxidants in vitro. J Am Chem Assoc 103, 6472-6477.

Cefalu, W. and Hu, F. (2004). Role of chromium in human health and in diabetes. Diabetes Care 27, 2741-2751.

Cherubini, A., Ruggerio, C., Polidori, M. and Mecocci, P. (2005). Potential markers of oxidative stress in stroke. Free Radicals in Biology \& Medicine 39, 841-852.

Chibber, R., Molinatti, P. A., Rosatto, N., Lambourne, B. and Kohner, E. M. (1997). Toxic action of advanced glycation end products on cultured retinal capillary pericytes and endothelial cells: Relevance to diabetic retinopathy. Diabetologia 40, 156-164.

Chidlow, G., Schmidt, K.-G., Wood, J., Melena, J. and Osborne, N. (2002). Alpha-lipoic acid protects the retina against ischaemic-reperfusion. Neuropharmacology 43, 1015-1025.

Cogan, D. and Kuwabara, T. (1967). The mural cell in perspective. Ophthalmology 78, 133-139.

Cossins, E., Lee, R. and Packer, L. (1998). ESR studies of vitamin C regeneration, order of reactivity of natural source phytochemical preparations. Biochemistry and Molecular Biology 45, 583-598.

Craven, P. A., Studer, R. K. and Derubertis, F. R. (1994). IMPAIRED NITRIC OXIDE-DEPENDENT CYCLIC GUANOSINE-MONOPHOSPHATE GENERATION IN GLOMERULI FROM DIABETIC RATS EVIDENCE FOR PROTEIN-KINASE C-MEDIATED SUPPRESSION OF THE CHOLINERGIC RESPONSE. Journal of Clinical Investigation 93, 311-320.

Craven, P. A., Studer, R. K., Felder, J., Phillips, S. and Derubertis, F. R. (1997). Nitric oxide inhibition of transforming growth factor-beta and collagen synthesis in mesangial cells. Diabetes 46, 671-681.

Cunningham, J., Mearkle, P. and Brown, R. (1994). Vitamin C: an aldose reductase inhibitor that normalises erythrocyte sorbitol in insulin-dependent diabetes mellitus. Journal of the American College of Nutrition 13, 344-350.

Defronzo, R., Tobin, J. and Andres, R. (1979). Glucose clamp technique: a method for quantifying insulin secretion and resistance. American Journal of Physiology 273, E214-223.

Di Mascio, P., Kaiser, S. and Sies, H. (1989). Lycopene as the most efficient biological carotenoid singlet oxygen quencher. Archives of Biochemistry and Biophysics 274, 1-7.

Dilley, R., a; Mcconnell,D,G. (1970). Alpha-tocopherol in the retinal outer segment of bovine eyes. Journal of Membrane Biology 2, 317-323.

Drevon, C. (1991). Absorption, transport and metabolism of vitamin E. Free Radical Research Commune 14, 229-246.

Ebara, T., Conde, K., Kako, Y., et al. (2000). Delayed catabolism of apoB-48 lipoproteins due to decreased heparan sulfate proteoglycan production in diabetic mice. Journal of Clinical Investigation 105, 18071818.

Fong, D., Aiello, L., Ferris, F. and Klein, R. (2004). Diabetic retinopathy. Diabetes Care 27, 2540-2553.

Forbes, J. M., Thallas, V., Thomas, M. C., et al. (2003). The breakdown of pre-existing advanced glycation end products is associated with reduced renal fibrosis in experimental diabetes. Faseb Journal 17, 1762-+. 
Forrester, J. V., Shafiee, A., Schroder, S., Knott, R., Mcintosh, L. and Lc (1993). THE ROLE OF GROWTHFACTORS IN PROLIFERATIVE DIABETIC-RETINOPATHY. Eye 7, 276-287.

Fosmark, D. S., Torjesen, P. A., Kilhovd, B. K., et al. (2006). Increased serum levels of the specific advanced glycation end product methylglyoxal-derived hydroimidazolone are associated with retinopathy in patients with type 2 diabetes mellitus. Metabolism-Clinical and Experimental 55, 232-236.

Fotsis, T., Pepper, M., Adlercreutz, H., Hase, T., Montesano, R. and Schweigerer, L. (1995). Genistein, a dietary ingested isoflavenoid, inhibits cell proliferation and in vitro angiogenesis. Proceedings of the National Academy of Sciences of the United States of America 90, 790S-797S.

Ganz, M. B. and Seftel, A. (2000). Glucose-induced changes in protein kinase C and nitric oxide are prevented by vitamin E. American Journal of Physiology-Endocrinology and Metabolism 278, E146-E152.

Giardino, I., Edelstein, D., Brownlee, M. and Nw (1994). NONENZYMATIC GLYCOSYLATION IN-VITRO AND IN BOVINE ENDOTHELIAL-CELLS ALTERS BASIC FIBROBLAST GROWTH-FACTOR ACTIVITY - A MODEL FOR INTRACELLULAR GLYCOSYLATION IN DIABETES. Journal of Clinical Investigation 94, 110-117.

Giardino, I., Edelstein, D., Brownlee, M. and Ub (1996). BCL-2 expression or antioxidants prevent hyperglycemia-induced formation of intracellular advanced glycation endproducts in bovine endothelial cells. Journal of Clinical Investigation 97, 1422-1428.

Ginsberg, H. N. (2000). Insulin resistance and cardiovascular disease. Journal of Clinical Investigation 106, $453-$ 458.

Grindlay, D. and Reynolds, T. (1986). The Aloe-Vera Phenomenon - a Review of the Properties and Modern Uses of the Leaf Parenchyma Gel. Journal of Ethnopharmacology 16, 117-151.

Gross, M., Steffes, M., Jacobs, D. R., et al. (2005). Plasma F-2-isoprostanes and coronary artery calcification: The CARDIA study. Clinical Chemistry 51, 125-131.

Guigliano, D., Cerellio, A. and Paolisso, G. (1996). Oxidative stress and diabetic vascular complications. Diabetes Care 19, 257-265.

Hammes, H. P., Du, X. L., Edelstein, D., et al. (2003). Benfotiamine blocks three major pathways of hyperglycemic damage and prevents experimental diabetic retinopathy. Nature Medicine 9, 294-299.

Handelman, G., Machlin, L. and Fitch, K. (1985). Oral alpha-tocopherol supplements decrease plasma gammatocopherol levels in humans. J Nutr 115, 807-813.

Hayashi, A., Weinberger, A., Kim, H. and De Juan, E. J. (1997). Genistein, a protein tyrosine kinase inhibitor, ameliorates retinal degeneration after ischemia-reperfusion injury in rat. Investigative Ophthalmology and Visual Science 38, 1193-1202.

Hayreh, S. (2001). The blood supply of the optic nerve head and the evalusation of it - myth and reality. Progress in Retinal and Eye Research 20, 563-593.

Heitzer, T., Finckh, B., Albers, S., Krohn, K., Kohlschutter, A. and Meinertz, T. (2001). Beneficial effects of alphalipic acid and ascorbic acid on endothelium-dependent, nitric oxide-mediated vasodilation in diabetic patients: relation to parameters of oxidative stress. Free Radical Biology and Medicine 31, 53-61.

Huang, S.-Y., Jeng, C., Kao, S.-C., Yu, J.-H. and Liu, D.-Z. (2004). Improved haemorrheological properties by Ginkgo biloba extract (Egb 761) in type 2 diabetes mellitus complicated with retinopathy. Clinical Nutrition 23, 615-621. 
Huebschmann, A. G., Regensteiner, J. G., Vlassara, H. and Reusch, J. E. B. (2006). Diabetes and advanced glycoxidation end products. Diabetes Care 29, 1420-1432.

Hunt, D., F; Organisciak,D,T; Wu,R,C (1984). Alpha-tocopherol in the developing rat retina: a high pressure liquid chromatographic analysis. Current Eye Research 3, 1281-1288.

Jacob, S., Ruus, P., Hermann, R., et al. (1999). Oral adminstration of RAC-alpha-lipic acid modulates insulin senstivity in patients eith type-2 diabeties meelitus: a placebo-controlled pilot trial. Free Radical Biology and Medicine 27, 309-314.

Jain, S. (1989). Hyperglycaemia can cause membrane lipid peroxidation and osmotic fragility in human red blood cells. Journal of Biological Chemistry 264, 21340-21345.

Jain, S. (1999). Should high-dose vitamin E supplementation be recommended to diabetic patients? Diabetes Care 22, 1242-1244.

Jan, S., Kannan, K. and Lim, G. (1998). Ketosis (acetoacetate) can generate oxygen radicals and cause increased lipid peroxidation and growth inhibition in human endothelial cells. Free Radicals in Biology and Medicine 25, 1083-1088.

Jha, H., Recklinghausen, G. and Zilliken, F. (1985). Inhibition of in vitro microsomal lipid peroxidation by isoflavonoids. Biochemical Pharmacology 34, 1367-1369.

John, W. G. and Lamb, E. J. (1993). THE MAILLARD OR BROWNING REACTION IN DIABETES. Eye 7, 230237.

Kagan, V., Khan, S. and Swanson, C. (1990). Antioxidant action of thioctic acid and dihydrolipoic acid. Free Radicals in Biology and Medicine 9S, 15.

Kaysen, G., Rathore, V., Shearer, G. and Depner, T. (1995). Mechanisms of hypoalbuminamia in hemodialysis patients. Kidney International 48, 510-516.

Keogh, R. J., Dunlop, M. E. and Larkins, R. G. (1997). Effect of inhibition of aldose reductase on glucose flux, diacylglycerol formation, protein kinase $\mathrm{C}$, and phospholipase A(2) activation. Metabolism-Clinical and Experimental 46, 41-47.

Kowluru, R. and Kennedy, A. (2001). Therapeutic potential of antioxidants and diabetic retinopathy. Expert Opinion on Investigational Drugs 10, 1665-1676.

Koya, D. and King, G. L. (1998). Protein kinase C activation and the development of diabetic complications. Diabetes 47, 859-866.

Lee, A. Y. W., Chung, S. S. M. and Yb (1999). Contributions of polyol pathway to oxidative stress in diabetic cataract. Faseb Journal 13, 23-30.

Levin, G., Yeshurun, M. and Mockady, S. (1997). In vitro antiperoxidative effect of 9-cis beta-carotene compared with that of the all-trans isomer. Journal of Nutrition in Cancer 27, 293-297.

Leydhecker, W. (1986). Zur medicamentösen behandlung der diabetischen retinopathie, The Ophthalmology Department of the University Clinic of Wurzburg.

Liu, X. M., Wei, J. P., Tan, F. S., Zhou, S. M., Wurthwein, G. and Rohdewald, P. (2004). Antidiabetic effect of Pycnogenol((R)) French maritime pine bark extract in patients with diabetes type II. Life Sciences 75, 2505-2513. 
Machlin, L. (1980). Vitamin E: a comprehensive treatise. Dekker, New York.

Machlin, L. and Bendich, A. (1987). Free radical tissue damage:protective role of antioxidant nutrients. FASEB Journal 1, 441-445.

Maisonpierre, P. C., Suri, C., Jones, P. F., et al. (1997). Angiopoietin-2, a natural antagonist for Tie2 that disrupts in vivo angiogenesis. Science 277, 55-60.

Mayer-Davis, E., Bell, R., Reboussin, B. A., Rushing, J., Marshall, J. and Hamman, R. (1998). Antioxidant nutrient intake and diabetic retinopathy: the San Luis Valley Diabetes Study. Ophthalmology 105, 22642270.

Mccance, D. R., Dyer, D. G., Dunn, J. A., et al. (1993). MAILLARD REACTION-PRODUCTS AND THEIR RELATION TO COMPLICATIONS IN INSULIN-DEPENDENT DIABETES-MELLITUS. Journal of Clinical Investigation 91, 2470-2478.

Mccord, J. M. (2000). The evolution of free radicals and oxidative stress. American Journal of Medicine 108, 652-659.

Millen, A., Gruber, M., Klein, R., Klein, B., Palta, M. and Mares, J. (2003). Relations of serum ascorbic acid and alpha-tocopherol to diabetic retinopathy in the Third National Health and Nutrition Examination Study. American Journal of Epidemiology 158, 225-233.

Millen, A., Klein, R., Folsom, A., Stevens, J., Palta, M. and Mares, J. (2004). Relation between intake of vitamins $\mathrm{C}$ and $\mathrm{E}$ and risk of diabetic retinopathy in the Atherosclerosis Risk in Communities Study. American Journal of Clinical Nutrition 79, 865-873.

Mullarkey, C., Eldstein, D. and Brownlee, M. (1990). Free radical generation by early glycation products: a mechanism for accelerated atherogenesis in diabetes. Biochemical and biophysical research communications 173, 932-939.

Murata, T., Nagai, R., Ishibashi, T., Inomata, H., Ikeda, K. and Horiuchi, S. (1997). The relationship between accumulation of advanced glycation end products and expression of vascular endothelial growth factor in human diabetic retinas. Diabetologia 40, 764-769.

Naim, M., Gestetner, B., Kirson, I., Birk, Y. and Bondi, A. (1973). A new isoflavone from soya beans. Phytochemistry 12, 169-170.

Nakajima, M., Cooney, M., Tu, A., et al. (2001). Normalization of retinal vascular permeability in experimental diabetes with genistein. Investigative Ophthalmology \& Visual Science 42, 2110-2114.

Nakamura, N., Hasegawa, G., Obayashi, H., et al. (2003). Increased concentration of pentosidine, an advanced glycation end product, and interleukin-6 in the vitreous of patients with proliferative diabetic retinopathy. Diabetes Research and Clinical Practice 61, 93-101.

Osborne, N., Melena, J., Chidlow, G. and Wood, J. (2001). A hypothesis to explain ganglioon cell death caused by vascular insults at the optic nerve head: possible implication for the treatment of glaucoma. British Journal of Ophthalmology 85, 1252-1259.

Packer, L. (2001a). Antioxidants and antioxidant enzymes: www.thaiwave.com/networkantioxidants/antioxidantenzymes.htm.

Packer, L. (2001b). Discovery of the antioxidant network: www.thaiwave.com/networkantioxidants/antioxidantnetwork.htm. 
Packer, L., Witt, E. and Tritschler, H. (1995). Alpha-lipoic as a biological antioxidant. Free Radicals in Biology and Medicine 19, 227-250.

Paolisso, G., Dimaro, G., Galzerano, D., et al. (1994). Pharmacological Doses of Vitamin-E and Insulin Action in Elderly Subjects. American Journal of Clinical Nutrition 59, 1291-1296.

Paolisso, G., D'amore, A. and Giugliano, D. (1993). Pharmacologic doses of vitamin E improve insulin action in healthy subjects and non-insulin dependent diabetic patients. Am J Clin Nutr 57, 650-656.

Portilla, D., Dai, G. H., Peters, J. M., Gonzalez, F. J., Crew, M. D. and Proia, A. D. (2000). Etomoxir-induced PPAR alpha-modulated enzymes protect during acute renal failure. American Journal of PhysiologyRenal Physiology 278, F667-F675.

Puttner, M., Grotemeyer, K., Wurthwein, G., et al. (1999). Inhibition of smoking-induced platelet aggregation by aspirin and pycogenol. Thrombosis Research 95, 155-161.

Raj, D. S. C., Choudhury, D., Welbourne, T. C. and Levi, M. (2000). Advanced glycation end products: A nephrologist's perspective. American Journal of Kidney Diseases 35, 365-380.

Rajasekaran, S., Ravi, K., Sivagnanam, K. and Subramanian, S. (2006). Beneficial effects of Aloe vera leaf gel extract on lipid profile status in rats with streptozotocin diabetes. Clinical and Experimental Pharmacology and Physiology 33, 232-237.

Rajasekaran, S., Sivagnanam, K. and Subramanian, S. (2005). Antioxidant effect of Aloe vera gel extract in streptozotocin-induced diabetes in rats. Pharmacological Reports 57, 90-96.

Roghdewald, P. (2002). A review of the French maritime pine bark extract (Pycnogenol®), a herbal medication with a diverse clinical pharmacology. International Journal of Clinical Pharmacology and Therapeutics 30, 158-168.

Seddon, J. M. (1999). Nutrition and age-related eye disease. Vitamin Nutrition Information Service. Backgrounder 2.

Shamoon, H., Duffy, H., Fleischer, N., et al. (1993). THE EFFECT OF INTENSIVE TREATMENT OF DIABETES ON THE DEVELOPMENT AND PROGRESSION OF LONG-TERM COMPLICATIONS IN INSULINDEPENDENT DIABETES-MELLITUS. New England Journal of Medicine 329, 977-986.

Shinohara, M., Thornalley, P. J., Giardino, I., et al. (1998). Overexpression of glyoxalase-I in bovine endothelial cells inhibits intracellular advanced glycation endproduct formation and prevents hyperglycemia-induced increases in macromolecular endocytosis. Journal of Clinical Investigation 101, 1142-1147.

Sinclair, A., Girling, A., Gray, L., Le Guen, C., Lunec, J. and Barnett, A. (1991). Disturbed handling of ascorbic acid in diabetic patients with and without microangiopathy during high dose ascorbate supplementation. Diabetologia 34, 171-175.

Sinclair, A., Girling, A., Gray, L., Lunec, J. and Barnett, A. (1992). An investigation of the relationship between free radical activity and vitamin $\mathrm{C}$ metabolism in elderly diabetic subjects with retinopathy. Gerontology 38, 268-274.

Singer, G. M. and Geohas, J. (2006). The effect of chromium picolinate and biotin supplementation on glycemic control in poorly controlled patients with type 2 diabetes mellitus: A placebo-controlled, double-blinded, randomized trial. Diabetes Technology \& Therapeutics 8, 636-643.

Spadea, L. and Balestrazi, E. (2001). Treatment of vascular retinopathy with Pycnogenol®. Phytotherapy Research 15, 219-223. 
Steele, V., Pereira, M., Sigman, C. and Kelloff, G. (1995). Cancer chemoprevention agnet development development strategies for genistein. Journal of Nutrition 125, 713S-716S.

Stitt, A., Gardiner, T. A., Anderson, N. L., et al. (2002). The AGE inhibitor pyridoxamine inhibits development of retinopathy in experimental diabetes. Diabetes 51, 2826-2832.

Stracke, H., Hammes, H. P., Werkmann, D., et al. (2001). Efficacy of benfotiamine versus thiamine on function and glycation products of peripheral nerves in diabetic rats. Experimental and Clinical Endocrinology \& Diabetes 109, 330-336.

Taddei, S., Virdis, A. and Ghaidoni, L. (1998). Vitamin C improves endothelium-dependent vasodilation by restoring nitric oxide activity in essential hypertension. Circulation 97, 2222-2229.

Tanaka, M., Misawa, E., Ito, Y., et al. (2006). Identification of five phytosterols from aloe vera gel as anti-diabetic compounds. Biological \& Pharmaceutical Bulletin 29, 1418-1422.

Timimi, F., Ting, H., Haley, E., Roddy, M., Ganz, P. and Creager, M. (1998). Vitamin C improves endotheliumdependent vasodilation in patients with insulin-dependent diabetes mellitus. Journal of the American College of Cardiology 31, 552-557.

Turner, R. C., Holman, R. R., Cull, C. A., et al. (1998). Intensive blood-glucose control with sulphonylureas or insulin compared with conventional treatment and risk of complications in patients with type 2 diabetes (UKPDS 33). Lancet 352, 837-853.

Van Den Enden, M., Nyengaard, J., Ostrow, E., Burgan, J. and Wiliamson, J. (1995). Elevated glucose levels increase retinal glycolysis and sorbitol pathway metabolism. Implications for diabetic retinopathy. Investigative Ophthalmaolgy and Visual Science 38, 1467-1470.

Van Der Hagen, A., Yolton, D., Kaminski, M. and Yolton, R. (1993). Free radicals and antioxidant supplementation: a review of their roles in age related macular degeneration. J Am Optom Assoc 64, 871-878.

Virgili, F., Kobuchi, H. and Packer, L. (1998). Procyanidins extracted from pinus Maritima (Pycnogenol((R))): Scavengers of free radical species and modulators of nitrogen monoxide metabolism in activated murine raw 264.7 macrophages. Free Radical Biology and Medicine 24, 1120-1129.

Visnon, J., Staretz, M., Bose, P., Kassm, H. and Basalyga, B. (1989). In vitro and in vivo reduction of erythrocyte sorbitol by ascorbic acid. Diabetes 38, 1036-1041.

Wang, H., Zhang, Z., Wen, R. and Chen, J. (1995). Experimental and clinical studies on the reduction of erythrocyte sorbitol-glucose ratios by ascorbic acid in diabetes mellitus. Diabetes Research in Clinical Practice 28, 1-8.

Watkins, P., Amiel, S., Howell, S. and Turner, E. (2003a). Diabetic eye disease. In: Diabetes and its management (eds P. Watkins, S. Amiel, S. Howell and E. Turner), Blackwell Publishing, Oxford, pp 144151.

Watkins, P., Amiel, S., Howell, S. and Turner, E. (2003b). Epidemiology of diabetes. In: Diabetes and its management (eds P. Watkins, S. Amiel, S. Howell and E. Turner), Blackwell Publishing, Oxford, pp 1622.

Wei, H. (1994). Isoflavones scavenge reactive oxygen species and protect DNA bases from oxidative DNA damage. Proceedings of the Annual meeting of the American Association for Cancer Research (Abstract 3690) 35, 619. 
Wei, H., Cai, Q. and Rahn, R. (1996). Inhibition of UV light and fenton reaction-induced oxidative DNA damage by the soybean isoflavone genistein. Carcinogenesis 17, 73-77.

Wei, H., Wei, L., Frankel, K., Bowenr and Barnes, S. (1993). Inhibition of tumor promoter-induced hydrogen peroxide formation in vitro and in vivo by genistein. Nutritional Cancer 20, 1-12.

Wei, M., Gaskill, S. P., Haffner, S. M. and Stern, M. P. (1998). Effects of diabetes and level of glycemia on allcause and cardiovascular mortality - The San Antonio Heart Study. Diabetes Care 21, 1167-1172.

Wei, Z. H., Peng, Q. L. and Lau, B. H. S. (1997). Pycnogenol enhances endothelial cell antioxidant defenses. Redox Report 3, 219-224.

Wilkinson, I., Megson, I. and Maccallum, H. (1999). Oral vitamin C reduces arterial stiffness and platelet aggregation in humans. Journal of Cardiovascular Pharmacology 34, 690-693.

Williamson, J., Chang, K., Frangos, M., et al. (1993). Hyperglycaemic pseudohypoxia and diabetic complications. Diabetes 42, 801-813.

Woff, S., Jiang, Z. and Hunt, J. (1991). Protein glycation and oxidative stress in diabetes mellitus and aging. Free Radicals in Biology and Medicine 10, 339-352.

World Health Organisation (2006). World Health Organisation/International Diabetes Federation, Definition and Diagnosis of Diabetes mellitus and intermediate Hyperglycaemia.

Xia, P., Inoguchi, T., Kern, T. S., Engerman, R. L., Oates, P. J. and King, G. L. (1994). CHARACTERIZATION OF THE MECHANISM FOR THE CHRONIC ACTIVATION OF DIACYLGLYCEROL-PROTEIN KINASEC PATHWAY IN DIABETES AND HYPERGALACTOSEMIA. Diabetes 43, 1122-1129.

Yamagishi, S., Amano, S., Inagaki, Y., et al. (2002). Advanced glycation end products-induced apoptosis and overexpression of vascular endothelial growth factor in bovine retinal pericytes. Biochemical and Biophysical Research Communications 290, 973-978.

Young, I., Tate, S., Lightbody, J., Mcmaster, D. and Trimble, E. (1995). The effects of desferrioxamine and ascorbate on oxidative stress in the streptozotocin diabetic rat. Free. Rad, Biol. Med. 18, 833-840.

Yue, D., Mclennan, S., Fisher, E., et al. (1989). Ascorbic acid metabolism and polyol pathway in diabetes. Diabetes 38, 257-261.

Yuyun, M., Alder, A. and Wareham, N. (2005). What is the evidence that microalbuminuria is a predictor of cardiovascular disease events? Current Opinion in nephrology \& Hypertension 14, 271-276.

Ziegler, D., Reljanovic, M., Mehnert, H. and Griess, F. (1999). Alpha-lipoic acid in the treatment of diabetic polyneuropathy in Germany: current evidence from cllinical trials. Experimental and Clincal Endocrinology and Diabetes 107, 421-430. 